\title{
La crítica adorniana a la fenomenología como preludio dialéctico de una lógica materialista
}

\author{
Adorno's critique of phenomenology as \\ dialectical prelude of a materialistic logic
}

\author{
Chaxiraxi M $\mathrm{M}^{\mathrm{a}}$ Escuela CRUZ \\ (Universidad de La Laguna)
}

Recibido: 01/04/2014

Aceptado: 12/11/2014

\section{Resumen}

El propósito de este artículo es prestar atención a la evolución de la lectura que hace Adorno de la fenomenología husserliana para abordar algunos de los problemas fundamentales que determinarán la formación materialista de su filosofía. Se pretende trazar la génesis de su pensamiento materialista desde su temprana afinidad con la obra de Cornelius, hasta los aspectos fundamentales de su filosofía de los años treinta.

Palabras clave: Fenomenología, Crítica inmanente, Materialismo, Dialéctica, Prioridad del objeto

\section{Abstract}

The main goal of this work is to investigate the evolution of Adorno's reading of Husserl's phenomenology, to present it as a central theme for the formation of his own materialistic philosophy. This article wants to trace the genesis of his thought, from his early fidelity to Cornelius' work, to the framework of his own philosophy in the 1930s.

Keywords: Phenomenology, Immanent critique, Materialismus, Dialectic, Priority of object 


\section{Introducción}

Desde sus primeras obras, Adorno asigna a la filosofía la responsabilidad de una tarea interpretativa que comprende como la crítica inmanente al nervio idealista, esto es, al principio de identidad y de sistema, con el objetivo de rescatar el momento de diferencialidad olvidado. «Sólo un filosofía no dialéctica que apunte a una verdad no histórica», escribe, «puede sostener que los viejos problemas podrían eliminarse simplemente olvidándolos o empezando desde el comienzo» 1 . Se refiere a un panorama filosófico que, incapaz de elaborar respuestas adecuadas a la crisis de fundamentación idealista, termina por reproducir y perpetuar ideológicamente la situación dada. Entre estas posiciones destaca el positivismo lógico, la Lebensphilosophie y la ontología fundamental heideggeriana. Sin embargo, especial interés tiene el diálogo que mantiene con la fenomenología de Husserl, pues, desde sus textos de los años veinte, representa una de sus principales preocupaciones intelectuales. Por eso, como se verá a continuación, la evolución de su diálogo con la filosofía de Husserl puede ser comprendida como «el preludio crítico-dialéctico para una lógica materialista» ${ }^{2}$, pues en ella no sólo se ve el modo en el que reconstruye el panorama filosófico de su tiempo a partir del interés por pensar de una forma distinta la teoría y la praxis. Supone, además, la base para comprender el significado de su filosofía materialista a partir de la noción de «crítica inmanente al idealismo». En estos textos se adelantan momentos de gran interés para el desarrollo de su pensamiento como, por ejemplo, la unión entre crítica filosófica y crítica social o su interpretación del sujeto trascendental, y se va dibujando lo que en los años sesenta llamará la «transición al materialismo» ${ }^{3}$. Esta transición significa en la obra de Adorno el rescate de la tradición materialista desde la base de una teoría crítica de lo social que, a partir de la señalización de la prioridad del objeto, convierte la dialéctica en materialista.

\section{La Dissertation sobre Husserl bajo la influencia de Cornelius}

La filosofía de Husserl fue el tema de la tesis doctoral de Adorno, presentada en 1924 con el título La trascendencia de lo cósico y lo noemático en la fenomenología de Husserl 4 . La importancia de este escrito en el periodo de formación de su dia-

\footnotetext{
1 Adorno, Th. W., Die Aktualität der Philosophie, en: Gesammelte Schriften, vol. 1, Frankfurt a.M., Suhrkamp, 1970-1986, p. 339. En adelante, la obra de Adorno será citada con la abreviatura (GS), seguida del tomo y el número de página correspondiente.

2 Adorno, Th. W./ Horkheimer, M., Briefwechsel 1927-1969, vol. 1, Frankfurt a.M, Suhrkamp, 2003, p. 41.

3 Negative Dialektik, en: GS 6, 193.

4 Die Transzendenz des Dinglichen und Noematischen in Husserls Phänomenologie, en: GS, 1, pp. 777.
} 
léctica materialista pone de manifiesto el lugar que ocupa en su pensamiento el diálogo con la fenomenología. Un diálogo que se inicia con esta obra de juventud, y que retoma durante los años treinta cuando elabora una serie de trabajos que conformarán su Metacrítica de la teoría del conocimiento. En el caso de la Dissertation, el componente crítico de su lectura de Husserl no es expresado de manera evidente, pues aún permanece apegado a las posiciones teóricas de su mentor académico, Hans Cornelius. Si bien es cierto que a partir de los años treinta matiza esta influencia y corrige algunas de las posiciones sostenidas en su primer trabajo, en él se asientan los fundamentos de un programa de crítica inmanente que se convertirá en un rasgo distintivo de su materialismo 5 .

Representante del neokantismo y lector crítico de la fenomenología husserliana, la filosofía de Cornelius entronca con una tradición de pensamiento ilustrada que surge como respuesta al estado de decadencia y crisis cultural de los años veinte. Considera la psicología de corte empirista como el fundamento de la teoría del conocimiento frente a la metafísica especulativa y a las llamadas Lebensphilosophie, tal como desarrolla en su obra Sistemática trascendental ${ }^{6}$. En ella explica la combinación entre el recurso a las vivencias inmediatas de la conciencia y la existencia de estructuras formales como base para la formación de conceptos y la percepción de la realidad. Esto supone una confrontación con la idea husserliana de lo «dado inmanentemente» y el concepto de intuición?. Estas ideas de Cornelius, sobre todo las referidas a su interpretación crítica de la fenomenología husserliana, serán el punto de partida de la tesis doctoral de Adorno.

La Dissertation propone una confrontación con los principios de la fenomenología con el objetivo de sacar a la luz sus contradicciones internas. Contradicciones que detecta en la teoría del objeto cuando aparecen en tensión distintos elementos idealistas y realistas que, en último término, acaban por invalidar el punto de partida del idealismo trascendental. Comienza poniendo en tela de juicio la pretensión de Husserl de desarrollar un idealismo trascendental basado en la idea de conciencia como fundamento del conocimiento. Se trata del interés de la fenomenología por indagar en los orígenes del conocimiento y por promover el establecimiento de la

\footnotetext{
5 Algunos intérpretes han visto en este texto la concreción de lo que llaman una «fase trascendental» en el pensamiento de Adorno, bajo la influencia de Cornelius. Sobre esto véase, Petazzi, C., «La fase trascendentale del pensiero di Adorno: Hans Cornelius», Rivista critica di storia della filosofia, 32, (1977), pp. 436-449.

${ }^{6}$ Cornelius, H., Transcendentale Systematik. Untersuchungen zur Begründung der Erkenntnistheorie, Münich, Ernst Reinhard, 1916.

7 Un estudio sobre la confrontación entre el psicologismo trascendental de Cornelius y la fenomenología de Husserl se encuentra en: Kern, I., Husserl und Kant. Eine Untersuchung über Husserls Verhältnis und zum Neukantianismus, Den Haag, Martinus Hijhoff, 1964. Véase también: Chrudzwimski, A., «Husserl and Cornelius», Husserl Studies, 8, (1991), pp. 33-56; y Cornelius, H., «Leben und Lehre», en: R. Schmidt (ed.), Die Philosophie der Gegenwart in Selbstdarstellungen, Leipzig, Feliz Meiner,1924, pp. 83-102.
} 
filosofía como ciencia rigurosa. Considera que con el concepto de «intuición originaria» Husserl pretende distanciarse de un concepto metafísico de «cosa en sí», así como de la forma de fundamentación naturalista que se basa en la comprensión de la experiencia inmediata como fuente de legitimación de todo juicio de conocimiento.

Sin embargo, Adorno encuentra una contradicción en el hecho de que Husserl atribuya a la cosa una trascendencia que, pese a que sólo puede mostrarse de modo inmediato en su relación con la conciencia, la convierte en poseedora de una existencia independiente. Por eso, es en la teoría del objeto donde cree ver el momento de tensión del planteamiento fenomenológico y, por tanto, también el lugar en el que la psicología trascendental de Cornelius podría actuar como su correctivo. Frente a la filosofía de Husserl, Cornelius insiste en considerar los resultados de la síntesis de los contenidos de conciencia como elementos a priori de los juicios empíricos. Tal como había argumentado en su discusión con Brentano, el problema reside en la teoría del objeto, esto es, en la forma de conciliar, por un lado, la suposición de la conciencia como fuente última de legitimidad y de fundamentación epistemológica y, por otro, la del objeto como trascendencia por principio que se da inmanentemente a la conciencia.

La forma de llevar a cabo esta conciliación en Husserl pasa por la epoché fenomenológica, según la cual la percepción de cosas se comprende como acto en el que el momento fenoménico de los objetos de conocimiento ha sido puesto «entre paréntesis». El interés de Adorno será «mostrar que en Husserl hay, efectivamente, una suposición inadmisible de la existencia de $\cos a s{ }^{8}$. Esto pone de manifiesto la presencia de una tensión entre componentes idealistas-trascendentales y realistastrascendentes que, en última instancia, contradice la realización del proyecto fenomenológico. Y la causa de esta contradicción la encuentra en el intento de legitimar la trascendencia de lo cósico en lo fenoménico. Pues Husserl pretende distanciarse de la psicología empirista dando una explicación de las cosas a partir de la descripción de las vivencias, pero termina por cometer una petición de principio cuando interpreta el momento de trascendencia como el elemento que diferencia entre la esfera de la conciencia y la de la realidad. La suposición de este principio trascendente contradice la idea matriz del idealismo trascendental, a saber: la suposición de la conciencia como fuente de legitimación del conocimiento y «esfera del ser de orígenes absolutos». Pues «la vaga trascendencia de la cosa respecto a su percepción se transforma en la dogmática trascendencia de la cosa respecto de la conciencia» 9 .

Esto conduce a Adorno a interpretar como verdadera tarea de la fenomenología no el análisis de la conciencia pura, sino la descripción de las leyes de la experien-

8 Die Transzendenz des Dinglichen und Noematischen in Husserls Phänomenologie, en: GS, 1, p. 27.

9 Ibid., p. 34. 
cia, algo que se expresa en el concepto de nóema. En la contraposición entre nóesis y nóema verá representada la que considera distinción principal de la teoría de conocimiento husserliana: la distinción entre el ser como conciencia y el ser como realidad. Y, siguiendo a Cornelius, rechaza interpretar el nóema como una trascendencia independiente a la conciencia, pues ve en él un «híbrido de cosa en sí inmanente y naturalista» ${ }^{10}$. De un lado, con la expresión nóema, Husserl pretende aludir al concepto de cosa en sí inmanente, si bien el momento de trascendencia que otorga a la cosa lo contradice. Y de otro, tampoco logra superar el concepto naturalista o realista del objeto por lo que cae en la contradicción de sus propios principios.

\section{Husserl y la aporía hispotasiada del idealismo}

Adorno se distancia años después de las ideas defendidas en su Dissertation, en concreto, de la orientación psicologista y empiriocriticista que impregnaba su primera lectura de Husserl. No obstante, el deseo de «comprender la génesis de la contradicción desde su raíz epistemológica, corregirla críticamente y mostrar sus consecuencias en el seno de la fenomenología sistemática» 11 seguirá siendo una constante cuando, en los años de exilio, retoma el nunca abandonado proyecto sobre la filosofía husserliana. Entre 1934 y 1937 trabaja, junto a Gilbert Ryle, en la investigación titulada The doctrines of intellectual intuition and intentionality in the phenomenological philosophy of Edmund Husserl, con la que pretende habilitarse en el Merton College de Oxford. Si bien no fue concluida, algunas de sus parten verán la luz en los años siguientes en forma de artículos a los que titula «Sobre la filosofía de Husserl» y «Husserl y el problema del idealismo» 12 .

En estos ensayos, Adorno no persigue comprender sistemáticamente la fenomenología husserliana, ni tampoco desarrollar las líneas maestras de su pensamiento. Pues abandona la llamada «filosofía como concepción del mundo» que había adoptado en el trabajo dirigido por Cornelius cuando trataba de mostrar las debilidades de la filosofía de Husserl. Lo que se desprende de estos textos, por el contrario, es

\footnotetext{
10 Ibid., p. 74

11 Ibid., p. 17

12 Zur Husserls Philosophie, en: GS, 20.1, pp. 46-118; y, Husserl and the problem of Idealism, ibid., pp. 119-134). Estos estudios se encuentran referidos casi con exclusividad a las Investigaciones lógicas y el primer tomo de las Ideas. Por tanto, no parece que Adorno haya tenido en cuenta la obra posterior de Husserl Crisis de las ciencias europeas y la fenomenología trascendental, en la que transforma algunas de las posiciones que se habrían sostenido en sus primeros libros, a partir de una crítica a la modernidad filosófica. Sobre esto, véase: Hentschel, R., Sache selbst und Nichtdenkungsgedanke. Husserls phänomenologische Region bei Schreber, Adorno und Derrida, Wien/Berlin, Turia \& Kant, 1992; y Wilke, S., «Adornos und Derridas Husserllektüre: ein Annäherungsversuch», Husserl Studies, 5, (1988), pp. 41-68.
} 
un cambio de perspectiva que afectará a su obra a partir de los años treinta13. Este cambio se materializa en el abandono progresivo del componente idealista de la filosofía trascendental de su mentor, así como en la adopción de un nuevo tipo de interpretación basado en la experiencia filosófica de la modernidad y en el papel representado por el impulso antimetafísico de la fenomenología. Como había señalado en La actualidad de la filosofía, el proyecto fenomenológico representaba uno de los principales intentos de dar salida a las aporías del idealismo. Por eso, se enfrenta a los textos de Husserl desde una perspectiva materialista que parte del deseo de discutir con ella desde «el espíritu de la dialéctica». Esto significa considerar la fenomenología como la mejor perspectiva desde la que poder expresarse una liquidación inmanente y dialéctica del sistema idealista ${ }^{14}$.

Adorno era consciente de que sólo en comunicación con las distintas voces filosóficas que se habían alzado tras el derrumbe del sistema idealista, era posible una transformación de la conciencia filosófica. Y encuentra la obra de Husserl entre estas voces como la más importante. La fenomenología se propone llevar a cabo la búsqueda de una forma distinta de fundamentación epistemológica basada en el análisis de lo dado objetivo y en su relación con las formas de conciencia. Con ello, pretende superar tanto el dogmatismo de la posición positivista, que se basa en la objetividad de la lógica y de la matemática, como también el relativismo psicologista, que reduce lo real a meras determinaciones de la conciencia. En este impulso ilustrado por «liberar a la razón crítica de los prejuicios contenidos en la religión ingenua y acrítica de los hechos» 15 , ve Adorno el componente crítico de la obra de Husserl. Pues la considera el último esfuerzo de la filosofía burguesa por «evadirse de su propio ámbito - la inmanencia de la conciencia y la esfera de la subjetividad constitutiva - utilizando para ello las mismas categorías que pone a su disposición el análisis idealista de la inmanencia de la conciencia»16. Su momento de verdad radica en el deseo de separarse de la engañosa reducción subjetiva con el fin de resaltar una experiencia propia del objeto. Por ello, en la consigna fenomenológica

\footnotetext{
13 A este respecto, Tiedemman y el resto de editores de la obra completa coinciden en resaltar esta transición cuando señalan: «si se quiere llamar por nombres, depende muy estrechamente de la separación de Cornelius y la unión a Walter Benjamin» (Editorische Nachbemerkung, en: GS, 1, p. 383).

14 Esta misma idea es expresada en una carta a Horkheimer: «se trata de hacer avanzar las contradicciones inmanentes de la fenomenología hasta su propia disolución, así como de dialectizar lo antidialéctico de todas las filosofías (...) Espero, por tanto, que pueda servir como prolegómeno a nuestra tarea teórica conjunta, es decir, a la lógica dialéctica, que mantengo la esperanza de poder llevar a cabo». (Th. W. Adorno/ M. Horkheimer, Briefwechsel 1927-1937, op.cit., p.56). En el manuscrito del ensayo «Sobre la filosofía de Husserl» se encuentra la siguiente dedicatoria: «para Max Horkheimer. Mi primer trabajo filosófico como prolegómeno del que será común. París, agosto, 1937». El texto mecanografiado se encuentra en el Theodor W. Adorno Archiv de Frankfurt a.M. (Ts. 322).

15 Husserl and the Problem of Idealism, en: GS, 20.1, p. 124.

16 Zur Husserl Philosophie, en: GS, 20.1, p. 52.
} 
de ir «a las cosas mismas» ve la voluntad antiidealista de rescatar el momento de objetividad que habría sido cercenado, utilizando para tal fin los propios medios de la conciencia.

Sin embargo, pretende mostrar también las dificultades a las que tuvo que hacer frente Husserl para abandonar por completo los presupuestos idealistas. Pues a pesar de que depura el componente especulativo del sistema, no lo hace estallar de forma definitiva y su «intento de fuga» del idealismo trascendental queda frustrado. En su Dissertation detectaba un momento de tensión entre los componentes idealistas y los realistas de la fenomenología que impedía una superación del idealismo. Ahora ve la causa de esta tentativa frustrada en el olvido del momento de mediación que tiene lugar en la teoría del objeto, y que no sólo obstaculiza la superación del relativismo y el dogmatismo, sino que además conduce a la repetición de las posiciones subjetivistas de las que pretendía escapar. Interpreta como la mayor paradoja de todos los intentos fenomenológicos «el haber pretendido obtener, a través de las mismas categorías que produjo el pensamiento subjetivo postcartesiano, esa objetividad que precisamente dichos intentos contradicen desde su origen» ${ }^{17}$. Por eso, aunque la fenomenología de Husserl se presenta contraria a aceptar la reducción a la espontaneidad subjetiva y oponga a ella la objetividad de la verdad, Adorno ve en la búsqueda de un fundamento epistemológico absoluto, una continuación de los motivos del sistema idealista. Pues se rebela contra el pensamiento reduccionista, pero utiliza para ello su mismo instrumento - el análisis de la estructura de la conciencia - como instancia en la fundamentación de los datos. De ahí que considere la fenomenología como el intento de destruir el idealismo desde dentro.

Su crítica a Husserl se centra en la noción de «intuición categorial», con la que éste pretendía resolver las dificultades que se planteaban tras el rechazo de la explicación psicologista de la verdad. La doctrina de la intuición categorial consiste en comprender las verdades ideales como manifestaciones de lo dado inmediatamente, desconectadas de los juicios de existencia empírica. En tanto verdades objetivas, se presentan a la conciencia como evidentes en sí mismas. Sin embargo, lo que Adorno ve en ella es el fracaso del esfuerzo fenomenológico de superar las posiciones realistas ingenuas en la fundamentación de la objetividad. Pues, según él, termina por conceder a la experiencia características que, en realidad, proceden del mismo proceso del pensamiento. Esto significa que el pretendido carácter inmediato que el método fenomenológico concede a la conciencia de las verdades ideales no es sino una característica extraída del acto de pensar. Por ello, si bien reconoce en la intuición categorial el deseo de trascender el ámbito del sistema idealista, piensa que Husserl acaba finalmente comprometido con las mismas categorías de la inmanencia subjetiva.

17 Die Aktualität der Philosophie, en: GS, 1, p. 327. 
En una carta a Benjamin, Adorno define la intuición categorial como la aporía hipostasiada del idealismo ${ }^{18}$, pues constituye el lugar en el que mejor se expresa el componente idealista de la fenomenología, un «tour de force por reconciliar el análisis de la conciencia con la esencia misma de la verdad»19. En ella, ve la maniobra con la que busca salvar la objetividad de la verdad frente al relativismo, junto a la comprensión ilustrada de la razón como fundamento último del conocimiento. Por eso, su crítica a la noción de «intuición categorial» como el espacio en el que ve coagulado el carácter paradójico del proyecto husserliano, no se centra en su dirección hacia un estado trascendental, sino en el esfuerzo que lleva a cabo por fundamentar la huida de la inmanencia de la conciencia en el análisis de la misma. Pues su comprensión de las esencias como verdades en sí se realiza a través de un modelo de explicación idealista cuando recurre al análisis de los datos de la conciencia como última instancia de fundamentación. Si bien en la llamada «a la cosas mismas» se expresa el antiidealismo de la fenomenología, su deseo de encontrar un primero absoluto a partir del cual derivar la comprensión de lo real la condena a quedar enredada en aporías que repiten, a su pesar, los instrumentos del sistema idealista de conocimiento que ansiaba disolver.

\section{La crítica a la intuición categorial y el «idealismo deteriorado»}

El entusiasmo con el que Adorno emprende su proyecto sobre la fenomenología durante estos años se deja ver en la correspondencia con Benjamin y Horkheimer, a quienes expresa la importancia que ésta representa para una construcción materialista y no dogmática de la filosofía: «Estoy convencido de que toda posición de la filosofía subjetiva de la inmanencia es realmente expresión de una conciencia de propiedad (...) Y casi no puedo dudar de que nuestra lógica está formada de acuerdo con las normas jurídicas que tienen a su vez vigencia para el sostenimiento de determinadas relaciones de producción» 20 . Motivado por esta concepción de su trabajo, propone a Horkheimer la publicación en la Zeitschrift del capítulo titulado «Crítica a la subjetividad trascendental», que entiende como un ataque decisivo al punto de partida de la filosofía idealista. En este trabajo ve el núcleo de su comprensión materialista de la dialéctica en el intento de comprender la confluencia entre la crítica al conocimiento y la crítica social, sobre la base del análisis de las categorías de sujeto y objeto en la teoría del conocimiento. Sin embargo, el interés no es compartido por Horkheimer, quien rechaza su publicación al acusar en él una falta de comprensión en todos los niveles de significado de los análisis de Husserl.

\footnotetext{
18 Adorno Th. W. / Benjamin, W., Briefwechsel 1928-1940, Frankfurt a.M., Suhrkamp, 1994, p. 179.

19 Husserl and the Problem of Idealism, en: GS, 20.1, p. 132.

20 Adorno, Th. W. / Horkheimer, M., op. cit., p. 101.
} 
Es interesante tener en cuenta la distinta valoración que ambos autores mantendrán con respecto a la fenomenología y a su posición como última expresión de la filosofía idealista. En el caso de Horkheimer, sus objeciones al trabajo son expuestas en una extensa carta que habría de influir de forma decisiva sobre el futuro inmediato de estos textos. En ella valora positivamente el haber tenido en cuenta las relaciones que ve entre la filosofía husserliana y la situación histórica presente. Horkheimer, que también se había habilitado junto con Cornelius ${ }^{21}$, comparte con Adorno su diagnóstico del fracaso que supuso el proyecto de una filosofía positivista no dogmática. Y entiende la filosofía de Husserl como el intento de «proporcionar una supervivencia (Fortexistenz) al idealismo burgués» ${ }^{22}$. No obstante, se muestra escéptico respecto a lo que constituye la pretensión que vertebra el trabajo de Adorno: la pregunta acerca de la posibilidad de llevar a cabo una liquidación inmanente al idealismo a partir de la crítica a la filosofía de Husserl.

Su principal objeción se centra en el intento de reconciliar la refutación del sistema idealista con la crítica a la filosofía husserliana y, en concreto, en la forma de crítica inmanente, pues ve en ella el error de querer pasar por encima del propio material fenomenológico. Se refiere al análisis de la intuición categorial llevado a cabo en estos trabajos, que considera insuficiente para mostrar una liquidación inmanente del idealismo. La falsedad del idealismo no se debe ni a su incapacidad para resistir a los criterios cientificistas de Husserl, señala, ni tampoco a su aceptación final por parte de éste. Por eso, considera que el gran error del análisis de Adorno es haber puesto en una relación «demasiado cercana» la cuestión de la revocación del idealismo con la fenomenología y la crítica a ésta. Con ello, asegura, introduce en la filosofía husserliana unas pretensiones que, finalmente, no logra satisfacer.

Estas reservas de Horkheimer hacen que no sea hasta 1956 cuando los trabajos vean la luz de forma unitaria bajo el título Metacrítica de la teoría del conocimiento 23 . Aquí diagnostica el carácter aporético de la fenomenología y propone hacer frente a la consecuencia que se deriva de este diagnóstico: su comprensión como el lugar desde el que es posible entender el fracaso del proyecto idealista dentro de sus propias categorías. De nuevo, verá el ejercicio de una liquidación del idealismo que entiende como el intento por «proceder con los razonamientos inmanentes del ene-

21 Husserls erkenntnistheoretische Fundierung der Wesensschau. Habilitations-Probevortrag, en: Horkheimer, M., Gesammelte Schriften, vol. 11, Frankfurt a. M., Fischer, 1985, pp. 80-99.

22 Adorno Th. W./ Horkheimer, M., op. cit., p. 428.

23 Zur Metakritik der Erkenntnistheorie. Studien über Husserl und die phänomenologischen Antinomien, en: GS, 5, pp. 7-247. Publicada por primera vez en 1956 en la editorial Kohlhammer, los capítulos primero, segundo y cuarto son resultado de la reeelaboración de los escritos de los años en Oxford, mientras que la introducción y el capítulo tercero serán redactados de forma novedosa. En las notas que cierran el libro, los editores alemanes insisten en señalar como al final de su vida Adorno continuaba valorando esta obra como una de las más importantes, junto a Dialéctica negativa. 
migo utilizando para ello la fuerza de nuestra propia comprensión trascendente, con el fin de que aquellos se rompan por sí mismos» 24 . Su metacrítica materialista pondrá el acento en los motivos del proyecto fenomenológico que le conducen a sucumbir en antinomias y, en consecuencia, a convertirse, a su pesar, en un «idealismo deteriorado».

Adorno comparte con Husserl el deseo de recuperar la objetividad del conocimiento y reconoce el valor de haber tomado partido por una realidad que no es encerrada en la inmanencia de la conciencia. Esto explica la defensa que hace del proyecto fenomenológico original frente a su interpretación por parte de sus sucesores, como Heidegger o Scheler, que lo convierten en ontología 25 . Sin embargo, también reconoce el peligro de buscar una fundamentación absoluta de la verdad basada en la hipóstasis tanto de la inmanencia de la conciencia como del dato inmediato. Por eso, ahora el acento cae sobre la idea de «lo inmediato», pues de ella se desprende el deseo de reducir las cuestiones epistemológicas a un único principio a partir del cual pretende explicar la totalidad de lo real26. En el recurso a la verdad absoluta y al conocimiento inmediato, finalmente, la fenomenología acaba convertida en una filosofía del origen, prolongación de la prima philosophia idealista.

\section{Absolutismo lógico, prima philosophia y cosificación}

Husserl pretende distanciarse del psicologismo a través de un proyecto fenomenológico basado en la idea de la filosofía como ciencia primera, orientada a la búsqueda de la «esfera de las objetividades ideales». En este interés por desarrollar una teoría del conocimiento apoyada en los fundamentos de un saber objetivo y universal, la ciencia lógica se convierte en su principal instrumento. La Metakritik de Adorno prestará atención a las dificultades que se dan en esta concepción de la lógica pura y, en concreto, a la idea de fundamentación de la objetividad, que entiende como «hipotética, especulativa y también, en cierta medida, metafísica» ${ }^{27}$. Y es que

\footnotetext{
24 Adorno Th. W./ Horkheimer, M., op. cit., p. 447.

25 Esto le distancia de la propuesta de Marcuse, quién creía ver en Heidegger un correctivo de la abstracción del pensamiento fenomenológico husserliano En una carta a Horkheimer, Adorno expresa las semejanzas y diferencias entre ambos trabajos: «comparto su intención de que en la forma de comportamiento fenomenológica existe un mal sucedáneo de praxis, en concreto, la praxis del erudito, que es hipostasiada. Sin embargo, también sería necesario mostrar un análisis crítico de la intención fenomenológica misma» (Ibid., p. 456).

26 Treinta años después, Adorno define el tema de este trabajo en una de sus lecciones universitarias como el deseo de reflexionar críticamente «sobre el intento global de la teoría gnoseológica en cuanto regresión al sujeto, en lugar de intentar hacer coincidir cualquier idea realista o materialista con los métodos apropiados de la crítica del conocimiento» (Philosophische Terminologie, vol. 2., Frankfurt a.M., Suhrkamp, 1973, p. 137).

27 Husserl and the Problem of Idealism, en: GS 20.1, p. 124.
} 
cuando Husserl pretende alejarse del relativismo otorgando a las entidades lógicas una realidad más allá del pensamiento, cae en la situación paradójica de un absolutismo lógico que, al mismo tiempo, sólo se concibe en el medio de la conciencia.

En sus trabajos de los años treinta, Adorno había definido la fenomenología como el pensamiento de la seguridad y de la resignación absoluta. En términos de la Metakritik, este afán de seguridad se traduce en el horror intellectualis ante lo casual y contingente, característico de la teoría moderna del conocimiento. Sus categorías, escribe, fueron pensadas para eliminar los «traicioneros restos de tierra» a favor de la identidad. Esto se muestra en la prioridad que la fenomenología otorga a las matemáticas y la lógica, que, gracias a la pureza de su método, se convierten en modelo desde el que medir los criterios de seguridad y certeza para el conocimiento $^{28}$. Al considerar las leyes lógicas independientes de la experiencia, Husserl les atribuye una validez en sí. Sin embargo, al querer superar también el idealismo neokantiano, obliga a situar el fundamento de la lógica en la conciencia. A juicio de Adorno, la teoría de la lógica pura fracasa al reproducir la misma voluntad totalitaria de la filosofía idealista contra la que se había constituido. Cuando intenta superar el relativismo, Husserl opone la prioridad del datum al fetichismo del concepto. Pero el resultado de la operación es distinto al que pretendía. Pues la determinación pura de la lógica tiene como equivalente el fetichismo tanto del objeto como el sujeto. De un lado, cuando convierte el dato en hipóstasis y lo presenta como independiente a lo existente, cae en la forma ingenua de realismo del que pretendía salir. De otro, al querer que sea captable de forma intuitiva por la conciencia, termina por repetir las mismas categorías idealistas de la inmanencia. Por eso, Adorno define el motor del pensamiento fenomenológico como «la voluntad de instaurar el Dasein, expulsado de la ratio, dentro del ámbito de la misma ratio autónoma» 29 . Husserl reproduce, por tanto, las categorías de las que había pretendido desligarse y admite, finalmente, el concepto idealista por excelencia: la subjetividad trascendental. Esto es, la idea de una conciencia como principio a partir del cual captar la totalidad del mundo, disolviendo aquello que no se ajusta a ella.

El momento idealista que Adorno detecta en la filosofia de Husserl consiste en su constante pretensión de identidad y de reducción a un principio absoluto. Pese a que observa un momento positivo en el concepto de «experiencia originaria», cuando se entiende como foco de resistencia en medio de la total cosificación de lo real,

28 En 1961 dedica parte de su lección sobre la relación entre ontología y dialéctica al concepto de «pureza» en las filosofías de Kant y Husserl. Pues si bien ve un momento de continuidad en ambos al pretender la disolución de lo empírico y lo transitorio, el camino seguido por la fenomenología es metódicamente distinto al kantiano: «Husserl comprende el concepto de pureza en un sentido escolástico, en tanto prioridad del concepto sobre lo real en él contenido» (Adorno, Th. W., Ontologie und Dialektik. 1960-61, en: Nachgelassene Schriften, vol. 7, Frankfurt a.M./Berlin, Suhrkamp, 2002, pp. 263-265).

29 Zur Metakritik der Erkenntnistheorie, en: GS, 5, p. 194. 
su hipóstasis resulta peligrosa. Y es que, en su opinión, toda teoría del conocimiento deviene prima philosophia cuando se hipostasía un principio originario desde el que se pretende alumbrar lo real y, frente al cual, todo lo demás es derivado y carente de valor. El ens concretissimus o dato inmediato comprendido como el último sustrato firme, es para Adorno el resultado de abstracciones, imposible de presentar como algo puro e independiente del trabajo categorial. Por eso, «lo que para la tradición era lo primero, la sensación o el material kantiano, se convierte para Husserl en lo último, en un telos convocado por un proceso del conocimiento, un cumplimiento final de la intención ${ }^{30}$. El recurso a las cosas mismas que la fenomenología pretende oponer al fetichismo de los conceptos constituye, en realidad, el producto del trabajo conceptual. Es una mezcla de historia y naturaleza. De esta forma, el elemento idealista que contradice el programa originario de la fenomenología reside, según Adorno, en su olvido de la relación irreductible que hay entre sujeto y objeto. El olvido del momento de mediación en el conocimiento, que provoca su conversión en prima philosophia, termina por reproducir esa misma fetichización que ansiaba superar.

Aquí reside el momento dialéctico que se encuentra en la voluntad anti-dialéctica de la filosofía husserliana y en virtud del cual la fenomenología se revoca a sí misma. A la trascendencia dogmática de la conciencia respecto a la experiencia que había defendido el sistema idealista se opone ahora una trascendencia inmanente igual de dogmática. Por eso, aunque el programa de la fenomenología se dirigía a eliminar la tiranía del psicologismo cosificado y a mostrar como alternativa la necesidad de ir a las cosas mismas, Adorno ve en ella un "sujeto disfrazado», signo de la propia cosificación que ansiaba evitar. En Husserl se cumple, irónicamente, la figura hegeliana del movimiento circular y dialéctico del pensamiento como el paradójico intento de una «teoría libre de teoría». Pues, si bien reflexiona sobre los fundamentos del conocimiento, al mismo tiempo, quisiera ir más allá del momento subjetivo de la crítica y entregarse a la datidad originaria. La Metacrítica insiste en desmontar la falacia de la teoría del conocimiento como una prima philosophia. Por eso, la alternativa a la reducción fenomenológica de Husserl, será una interpretación materialista de la dialéctica capaz de tomar conciencia del necesario carácter mediado de lo real y de la experiencia filosófica.

\section{Dialéctica y mediación en la filosofía materialista}

Desde sus primeros trabajos, Adorno comprende la crítica al idealismo como crítica a la filosofía del origen. El espíritu idealista explica el mundo como extensión de un yo capaz de determinar lo objetivo. Olvida, con ello, su propia génesis,

30 Ibid., p. 153. 
y se convierte en prima philosophia. La contraimagen del principio idealista es la conciencia del momento de irreductibilidad y de mediación que se da en la experiencia concreta del conocimiento. Por eso, la metacrítica materialista sirve de correctivo tanto al desmesurado subjetivismo idealista como a cualquier entronización del objeto como dato sensible inmediato. Insistir en la mediación de lo que se presenta como inmediato supone distanciarse de la experiencia ingenua y pre-crítica del objeto que reside en el giro fenomenológico hacia las cosas mismas ${ }^{31}$. Pues esto supondría depurarlo, descualificarlo y, en definitiva, repetir las posiciones del realismo positivista que lo convierte en «raquítico» y abstracto. En este caso, la teoría termina por claudicar ante lo existente sin ofrecer resistencia, y renuncia a cualquier posibilidad de crítica.

De la lectura adorniana de Husserl se desprende, pues, el interés que pervive en ella por hacer cumplir las intenciones originarias de la fenomenología que se habían quedado a medio camino. Cumplir con las expectativas del proyecto fenomenológico de alcanzar un fundamento objetivo para la verdad no pasa por aislar éste del momento subjetivo, sino por reconocer su contenido real. Por eso, ir «a las cosas mismas» no significa comprender el objeto como dato inmediato. Se trata de obligar a la teoría a descubrir el momento de mediación de lo que se presenta como inmediato. Y aquí reside el momento crítico de su dialéctica negativa que destaca frente a la subjetividad hipostasiada del idealismo y a la falsa objetividad del positivismo. Por eso, frente al realismo ingenuo que ve en la teoría husserliana del objeto, la filosofía materialista opone la llamada «prioridad del objeto».

Es importante ver el momento de comunión entre ambas figuras en lo que concierne a la crítica a la superioridad del idealismo y a la comprensión de la identidad de la conciencia como sustrato del conocimiento. Pues ve en Husserl, por primera vez desde el derrumbe de los grandes sistemas, un testimonio fiel de «la insuficiencia del individuo como fundamento legítimo de la verdad»32. Pero, a diferencia de éste, la «prioridad del objeto» incorpora el momento de la mediación y, con ello, le atribuye también una dimensión crítico-descriptiva: refleja la prioridad del todo social real respecto a lo individual y, como consecuencia, la desintegración de lo individual mismo. Por eso, la crítica inmanente no significa únicamente dar cuenta de las contradicciones que surgen en la teoría del conocimiento, sino también mostrar el momento de verdad que reside en ella. Un momento de verdad que, en este caso, consiste en la representación de las aporías de lo social.

\footnotetext{
31 «El fenomenólogo no puede pensar los objetos de forma distinta que como subjetivamente constituidos, pero al mismo tiempo éstos se encuentran para él tan alienados y cosificados, que los ve y los describe como segunda naturaleza, olvidando que, una vez despertados, vuelven a disolverse inmediatamente en determinaciones puramente subjetivas» (Zur Philosophie Husserls, en: GS, 20.1, p. 59). 32 Zur Metakritik der Erkenntnistheorie, en: GS, 5, p. 96.
} 


\section{La fenomenología como sismógrafo histórico}

El interés de Adorno se encuentra en la tarea de «hacer saltar la chispa de la concreción histórica, justamente allí donde se presenta en su forma más abstracta» 33 . En la pretensión de alcanzar una determinación pura de la lógica se esconde un contenido social concreto que quiere sacar a la luz la dialéctica materialista. Pues ve en ella no sólo el impulso idealista del sujeto que quiere alejarse de lo objetivo-material y que se reduce a la inmanencia de la conciencia, sino también un testimonio de la desintegración a la que se ve sometido el sujeto real. En la fenomenología está recogida la idea de los antagonismos de la existencia actual, de ahí que considere su filosofía un fiel sismógrafo histórico ${ }^{34}$. El absolutismo lógico refleja ambas cosas: la reflexión sobre los peligros del sujeto idealista y, también, el intento de superar la tiranía de la subjetivización universal, oponiéndole el recurso a lo absolutamente distinto e irreductible.

En sus categorías, la filosofía de Husserl pone de manifiesto una representación de la cosificación que se da en la realidad y a la que se encuentran sometidos tanto el objeto como el sujeto. Éste es el momento de mayor realismo que Adorno encuentra en la teoría del objeto husserliana para una liquidación inmanente del idealismo. Por eso, escribe, «la lógica enajenada de toda realidad le opone su nulidad real»35. Se desprende de aquí su interés por mostrar la mediación que existe entre las categorías lógicas de la filosofía idealista y la realidad sociohistórica que se encuentra coagulada en ellas. El momento positivo de Husserl consiste en haber «arrancado la síntesis y la historia a la cosa petrificada», pues al hacerlo manifiesta las contradicciones inmanentes al proyecto fenomenológico para, finalmente, conducirlas hasta el lugar en el que quedan revocadas. Por eso, representa el deseo materialista de sacar a luz las condiciones ocultas que permanecen cosificadas para, como había expresado Marx, «tocarles su propia melodía». En el reconocimiento de la nulidad del sistema idealista, del carácter aporético de sus conceptos y, junto a ello, del momento de verdad que representa en su contenido social, ve el mérito de la filosofía de Husserl, y el lugar desde el que es posible interpretar una auténtica liquidación materialista del idealismo.

33 Adorno, Th. W. /Horkheimer, M., op. cit., p. 41.

34 Horkheimer había resaltado la importancia de esta idea del joven Adorno cuando, en una carta dirigida a éste en 1936, escribe: «el hecho de que usted quiera destruir el sujeto trascendental de Husserl a través de la prueba inmanente de su pertenencia a la existencia del cuerpo (Leib), nos ha sorprendido mucho a todos. Si esta intención llegara a cumplirse, entonces habrá proporcionado al materialismo un gran servicio» (Ibid., p. 215).

35 Zur Metakritik der Erkenntnistheorie, en: GS, 5, p. 96). Benjamin elogia en una carta el deseo llevado a cabo en el trabajo de Adorno por desarrollar una crítica social de la lógica como un «proyecto nuevo y apasionante» (Adorno Th. W. / Benjamin, W., op. cit., p. 185). 
La alternativa que Adorno propone a la fenomenología de Husserl será una orientación materialista de la dialéctica que parta de una «constelación de factores» distinta a la reducción entre sujeto y objeto del conocimiento. Pues no comprende la dialéctica "como una concepción del mundo en cuyos esquemas se habría de prensar la realidad» ${ }^{36}$, sino como el esfuerzo de la razón por reflexionar sobre sí misma a partir de la experiencia crítica del objeto. Por eso, el principio de crítica inmanente se opone al método comprendido como «una forma de proceder del espíritu que puede utilizarse de forma general y segura, porque ha sido despojado de la relación con la cosa, con el objeto de conocimiento» 37 . Ser conscientes de las mediaciones y sacarlas a la luz supone, finalmente, la indicación fundamental de un proceder crítico inmanente. Idea que será uno de los hilos conductores que recorrerán la obra completa de Adorno y un aspecto central en la construcción de su filosofía materialista.

Chaxiraxi $\mathrm{M}^{\mathrm{a}}$ Escuela Cruz

Universidad de La Laguna

cescuela@ull.edu.es

36 Drei Studien zu Hegel, en: GS, 5, p. 258.

37 Zur Metakritik der Erkenntnistheorie, en: GS, 5, p. 19. 